\title{
A Novel Experiment to Study the Roll Motion Characteristics of a Sailing Ship in a Landslide-Generated Wave in the Three Gorges Reservoir
}

\author{
Peiyin Yuan $\mathbb{D}^{1,2}$ Pingyi Wang, ${ }^{1}$ and Yu Zhao ${ }^{1,3}$ \\ ${ }^{1}$ College of River and Ocean Engineering, Chongqing Jiaotong University, Chongqing 400074, China \\ ${ }^{2}$ College of Shipping and Naval Architecture, Chongqing Jiaotong University, Chongqing 400074, China \\ ${ }^{3}$ College of Architecture and Urban Planning, Chongqing Jiaotong University, Chongqing 400074, China
}

Correspondence should be addressed to Peiyin Yuan; yuan_pei_yin@163.com

Received 24 April 2019; Revised 15 May 2019; Accepted 21 May 2019; Published 2 July 2019

Guest Editor: Endong Wang

Copyright (c) 2019 Peiyin Yuan et al. This is an open access article distributed under the Creative Commons Attribution License, which permits unrestricted use, distribution, and reproduction in any medium, provided the original work is properly cited.

Strong earthquakes, heavy rains, changes in reservoir water levels, and other external factors destabilize large rock masses causing them to fall into the water at high speed, thereby destroying the original ecological balance in the region. These occurrences cause fluctuations in water levels and form landslide-induced waves, which behave similar to tsunamis upon reaching the shore, a dam structure, or ships. The impact invariably threatens residents' lives and properties in the upper and lower reaches of the reservoir area. In the current study, we conducted orthogonal experiments of landslide-induced impulse waves to assess their related hazards. To explore the effects of a landslide-generated wave on the roll characteristics of a ship, experimental model tests were performed using different speed vessels, landslide bodies, and navigation positions. Accordingly, a reasonable optimization strategy was proposed to provide technical support for ship navigation safety in regions of landslide-generated waves.

\section{Introduction}

External factors such as earthquakes, heavy rain, and changes in reservoir water levels can cause rapid and violent sliding of slope rock and soil masses [1]. Numerous landslide bodies interact with water to excite waves, which have an inestimable direct impact on rivers, lakes, and passing vessels (i.e., ship) - even when a ship is suspended or prohibited from navigation. Other effects include damage to hydraulic structures in the reservoir, causing dams to burst; destruction of downstream farmland, houses, railways, and roads; and threatening the safety of life and property of urban residents $[2,3]$.

Recent research efforts investigating landslide-generated waves have been productive. The formation, propagation, and run-up of landslide-generated waves have been studied through simple physical experiments $[1,4-6]$, analytical formulae $[7,8]$, scale-model physical experiments [9-11], and numerical simulations [12-16]. Furthermore, wave types, water body geometry effects, block model parameters, and wave kinematics have been systematically studied by Heller and others [17-21].

Extensive research has been conducted on the behavior of ships using theoretical analysis [22-26], the method of simulation [27-30], the strip theory [31], the novel technique [32], physical experiments [33,34], and comparative analysis of numerical and experimental results [35].

Based on the literature review, little work has been reported on the motion characteristics of sailing ships in relation to impulse waves. The current study is based on the Three Gorges Reservoir region. We focused on the interaction between the landslide-generated wave and ship, investigated the propagation characteristics of the landslide-generated wave, and explored the effect of a landslide impulse wave on the roll characteristics of a ship, which can provide reasonable speed and position references for navigation of ships with the results of a model test. 


\section{Model Experiment Design}

Before the test, all rock-soil was placed above water. The defining characteristic of a landslide into water was the rock-soil mass being completely submerged after deposition during the test, which was accounted for during our experimental design. Experimental landslide blocks were made of concrete, with $2300-2400 \mathrm{~kg} / \mathrm{m}^{3}$ density, similar to that of a rock-soil mass. The ratio of these dimensional geometric parameters was determined based on the geometric parameter ratio of landslides in the Three Gorges Reservoir. The limiting criteria for scale models of impulse waves generated by subaerial landslides including solid, air, and water are discussed based on the literature review and detailed two-dimensional experimentation. Scale effects were primarily attributed to impact crater formation, in addition to air entrainment and detrainment. The reasonable Froude similitude was conducted, including intermediate-water wave spectrum, before the experiment was performed.

Five experiments were performed for each group: the first experiment was to determine the initial impulse wave's position and to affix the wave gauges, the second experiment was to determine the position of the container ship and to improve measurement accuracy, and the others were to acquire the initial wave's height and the ship's motion values regarding the roll and pitch. Subsequently, average data values were calculated and were considered to be the group's experimental result values.

2.1. Sliding Body Experiment Design. In the model test, the landslide rock was generalized into a rectangular parallelepiped shape, with a $1 \mathrm{~m}$ set length. This was combined with aspect ratio statistics of the landslide body in the reservoir area by controlling sliding body volume using different aspect ratios. This allowed us to investigate different impulse wave characteristics produced by the same volume at varying sliding body aspect ratios. The sliding blocks were generated according to the actual landslide situation, composed of different granular sizes (Figure 1). A net was placed above the slope in the model test process to ensure that the landslides reach the specified angle and prevent landslides sliding prior to the model test. Net properties were adjusted to keep the friction angle at 40 degrees.

2.2. Slip Angle Design. According to numerous statistics on the sliding surface gradient of landslides in a reservoir area, the landslide sliding surface slope was distributed between $20^{\circ}$ and $60^{\circ}$, with an average of $40^{\circ}$. At the same time, considering the test's operability factor and energy conversion efficiency, a $40^{\circ}$ inclination angle was chosen for the sliding surface during this test. Water-level collectors were used to detect water-level changes in the channel river. Seven water-level collectors were placed at designated spots. Pressure sensors were installed on water-level collectors, and pressure values were captured and converted into waterlevel values.

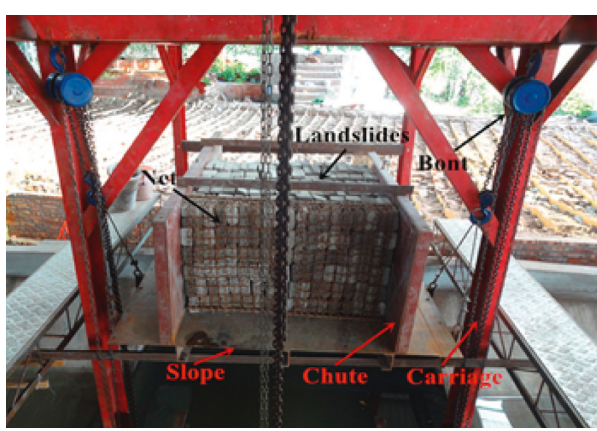

FIgURE 1: Arrangement of sliding blocks.

2.3. River Channel Model Design. The reservoir's geometry scale was 1:70. During the Three Gorges Reservoir operation, three water levels of 145,155 , and $175 \mathrm{~m}$ were mainly present. Considering the reservoir's actual water level and the river's water depth, according to the geometric scale model, water depths were $0.74,0.88$, and $1.16 \mathrm{~m}$. In this paper, a $0.74 \mathrm{~m}$ water depth was selected as the research subject. The river model width was $8 \mathrm{~m}$, and the ship's navigation position distance was $0.5 \mathrm{~m}$ from the navigation center line. The distance between monitoring points 1 and 3 was $8.94 \mathrm{~m}$ from the landslide entry point, and the landslide point distance was $3.3 \mathrm{~m}$. Monitoring point 1 was located at the straight end of the river, monitoring point 2 at the landslide section, and monitoring point 3 at the bend of the river. Figure 2 shows the river channel model layout, and Figure 3 shows the river channel model.

2.4. Ship Model Design. The ship model-designed to the scale of 1:70-was based on the Froude similarity [6]. The $3500 \mathrm{~T}$ container ship was selected as the model type for this study. During the model test, (1) the ship's drive was controlled by a servo motor; (2) its speed was accurately controlled at $0.3,0.5$, and $0.7 \mathrm{~m} / \mathrm{s}$; (3) the ship was fully loaded; (4) its draught was controlled by adding various types of weights; and (5) the ship's motion amplitude and roll acceleration were independently designed and developed. Parameters of the ship model are listed in Table 1. Disk ratio is the ratio of the average height to the critical length of a rudder.

Figure 4 shows photographs of the ship's plan and experimental models.

\section{Experimental Verification}

3.1. Experimental Verification of Landslide-Generated Wave. In order to verify the correctness of the model test, the experimental model was similar to Heinrich's model [36]known in the field for its high accuracy and representativeness-with the same model test parameters. The landslide body size was $0.5 \mathrm{~m} \times 0.5 \mathrm{~m}$. Slope angle was 45 degrees, water depth was $0.4 \mathrm{~m}$, and the landslide body slid under gravity. Our experimental results concurred with Heinrich's results, as shown in Figure 5. Our experimental results have increasing phase at the beginning while Heinrich's do not. This is due to two main reasons. One reason is that landslide 


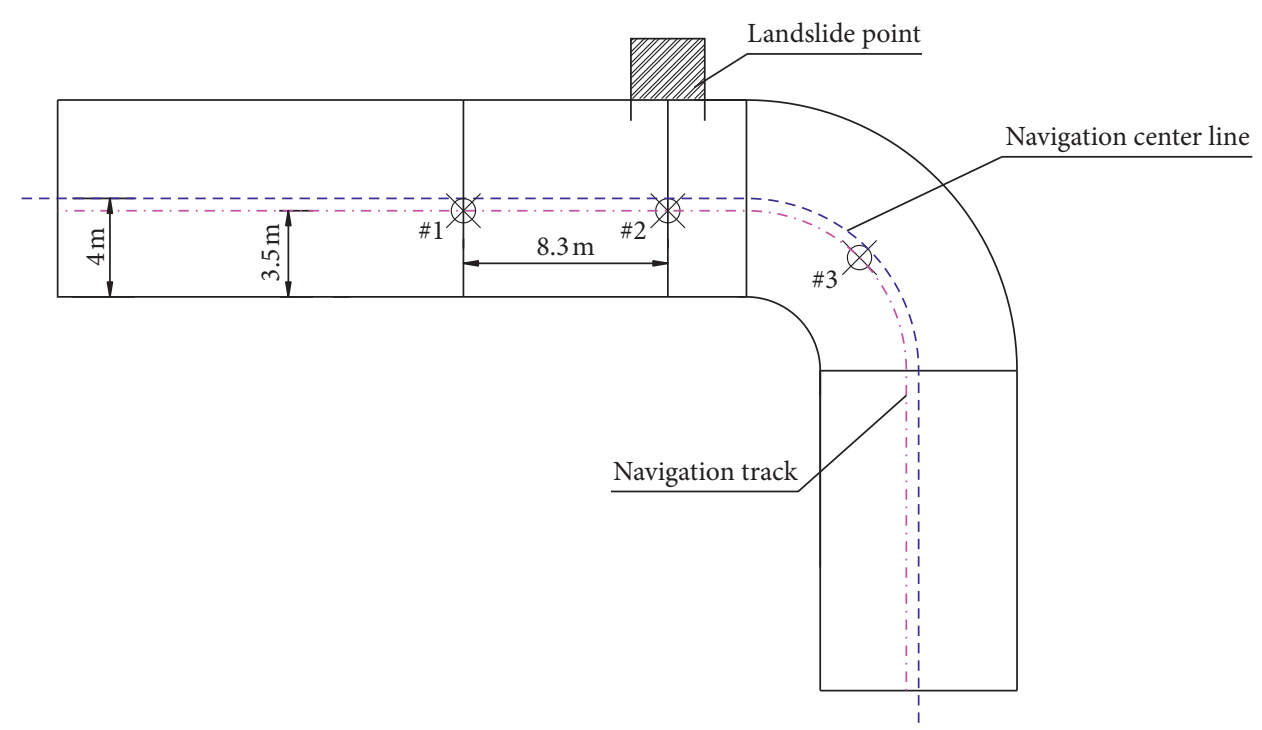

Figure 2: Layout of the river channel model.

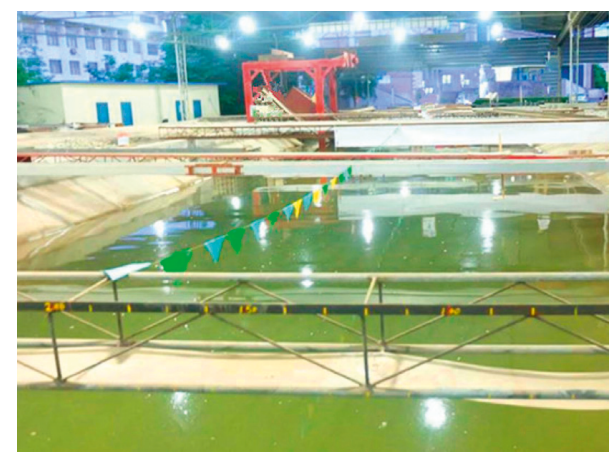

FIGURE 3: River channel model.

TABle 1: Primary parameters of the ship.

\begin{tabular}{lcc}
\hline Parameter & Real ship & Ship model \\
\hline Length $(\mathrm{m})$ & 94.5 & 1.350 \\
Beam $(\mathrm{m})$ & 15.1 & 0.216 \\
Moulded depth $(\mathrm{m})$ & 9.0 & 0.129 \\
Draught $(\mathrm{m})$ & 5.6 & 0.08 \\
$C_{\mathrm{b}}$ & 0.7 & 0.7 \\
$C_{\mathrm{p}}$ & 0.69 & 0.69 \\
Displacement $(\mathrm{t} / \mathrm{g})$ & $3500 \mathrm{t}$ & $10,150 \mathrm{~g}$ \\
Area of rudder $\left(\mathrm{m}^{2} / \mathrm{cm}^{2}\right)$ & 14.3 & 2.9 \\
Rudder height $\left(\mathrm{m} / \mathrm{cm}^{2}\right)$ & 4.1 & 5.9 \\
Aspect ratio of the propeller & 1.72 & 1.72 \\
Number of blades, $Z$ & 4 & 4 \\
Propeller diameter $(\mathrm{m} / \mathrm{cm})$ & 3.1 & 4.4 \\
Screw pitch $(\mathrm{m} / \mathrm{cm})$ & 2.6 & 3.7 \\
Disk ratio of rudder & 0.67 & 0.67 \\
\hline
\end{tabular}

body slides into the channel, the wave peak of the landslidegenerated wave is steep, and it has a large amount of splashing liquid; hence, it is hard to monitor the water level. The other reason is that the number of water-level collectors is closely arranged, which can accurately monitor the change in the water level. These data show that the experimental model can be accurately applied to the case of landslidegenerated waves.

3.2. Free Attenuation Test. Roll decay tests in calm water were performed, which mainly verified the ship's loading conditions. Damping present in a ship's roll motion is assessed via a free decay experiment. In the absence of waves, the ship is given initial roll amplitude and then released. By processing the resulting decaying oscillatory trace, it is possible to estimate quantitatively the degree of damping, even when this is nonlinear. The ship's freedom degree in the vertical plane exhibits the recovery characteristic. The ship model deviates from the position of equilibrium under external loading. When the external force disappears, the ship returns to its original position, depending on its own recovery characteristic. In a free roll decay test, the model is heeled in calm water to an initial heel angle and released. The model starts to perform free decaying oscillations at a frequency depending on the amplitude. Subsequently, the accuracy of the model test can be verified. The roll motion's decay curve is shown in Figure 6. The test results demonstrate that the ship's decay meets loading condition requirements, and the experimental data were used to tune the ship's hydrodynamic inertia properties, the natural roll period, the roll damping, and the inertia.

\section{Study of Landslide-Generated Wave Propagation Characteristics}

Experimental observation of the landslide-generated wave during the initial wave formation revealed that the landslide body interacts nonlinearly with the water body-the landslide body completely enters the water and the water surface rises rapidly. Once the energy is fully exchanged, two types of waves are generated: the oscillating wave, which is the reciprocating movement of the induced water quality point around its original position, and the passing wave, which 


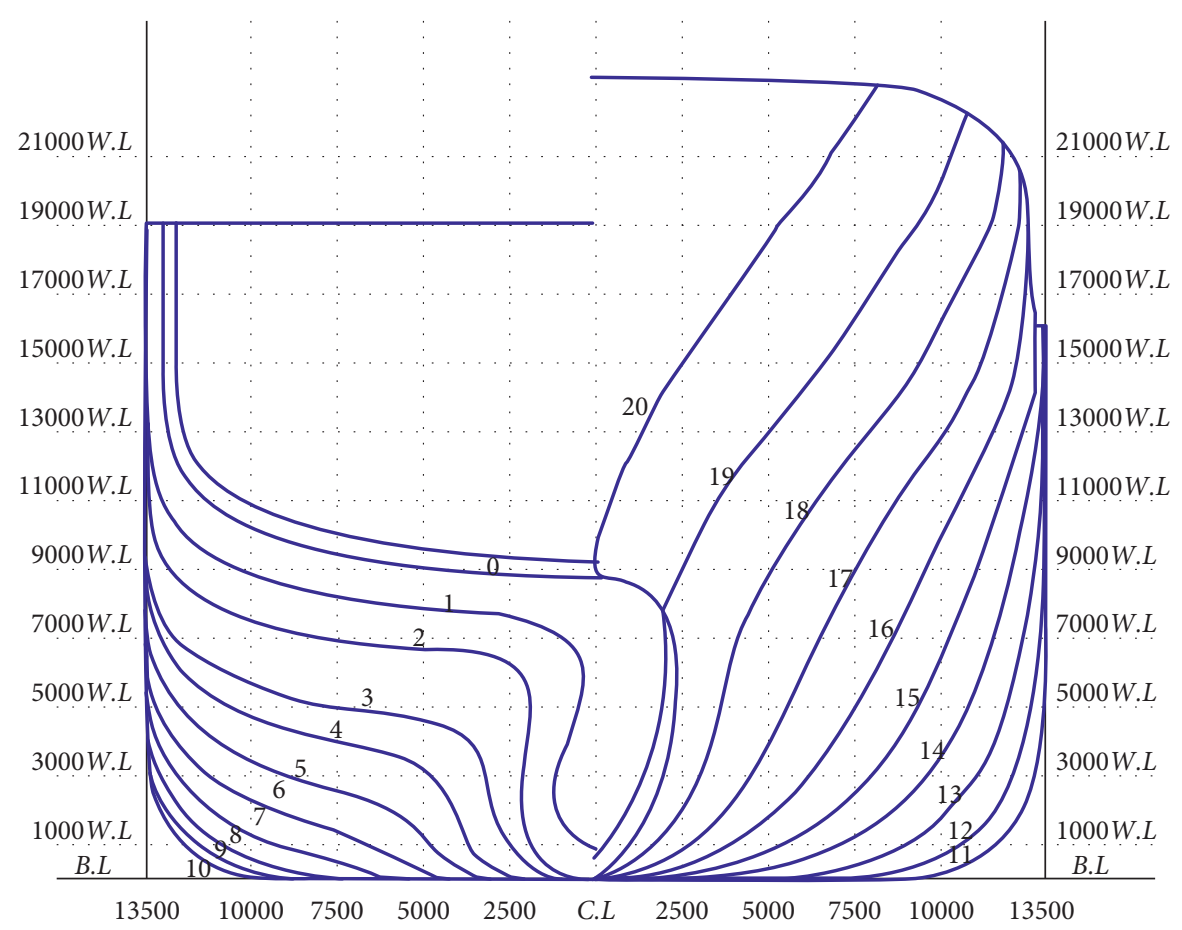

(a)

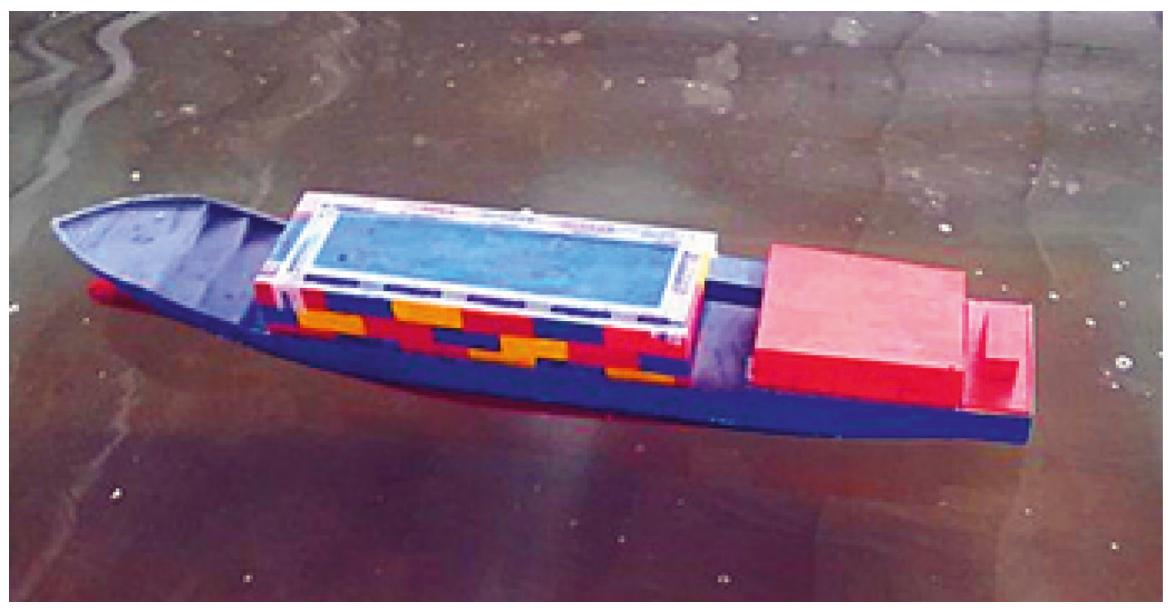

(b)

Figure 4: (a) Plan of the ship model; (b) experimental model.

originates from the forward movement of the landslide body, causing the water quality point to move forward and generate a ridge height and hence spreading the water particles in different directions.

\subsection{Landslide-Generated Wave Condition Design for Rock} Mass. There were 45 cases in the physical model test. The volume of the landslide, navigational position of the ship, and speed of the ship were single-factor variables. The specific working conditions are listed in Table 2.

4.2. Study on the Height of the Landslide's First Wave. Impulse waves are formed by a rapid or impulsive transfer of momentum from a mass flow to a water body. The wave generator is the landslide, which may be considered as a moving object disturbing the water. Not all landslide energy is transferred onto the water body. In the experiments, frictional losses are due to the bed friction between the landslide and the slope. Therefore, part of the landslide energy is taken out of the system or lost in the slide's internal deformation. Water displacement resulting in an uplift or hump at the free surface forms the potential energy.

In this work, we studied different height trends of the first wave generated by the landslide caused by the same volume at different width-thickness ratios. The first wave height-monitoring point of the landslide body was located at $1.5 \mathrm{~m}$ from the water inlet point of the landslide body. Flow separation on the rockslide shoulder, due to fast slide 


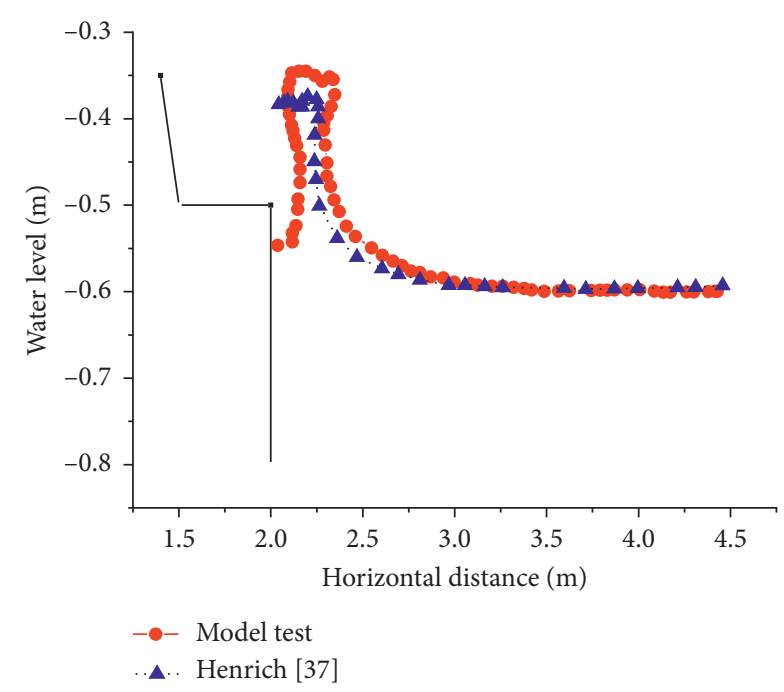

Figure 5: Comparison between Heinrich's [36] and the experimental free surface at $0.6 \mathrm{~s}$.

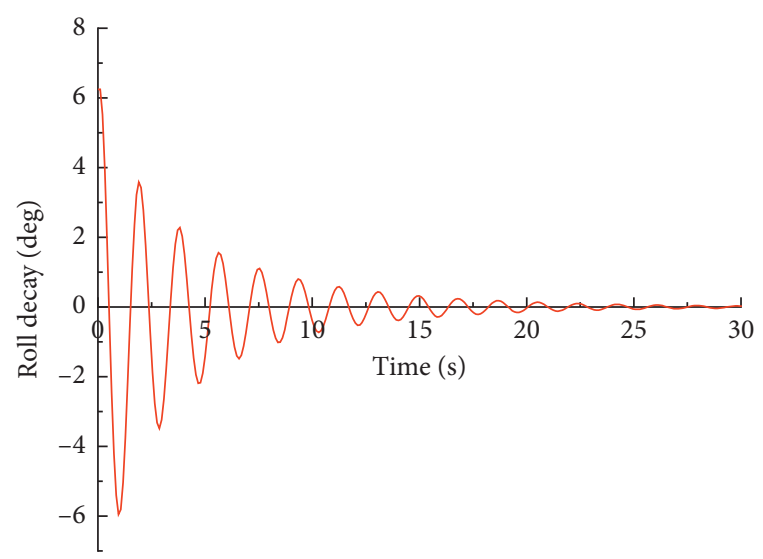

FIgURE 6: Roll motion decay curve.

TABLe 2: Table of cases.

\begin{tabular}{lccccc}
\hline Case & $\begin{array}{c}\text { Entry } \\
\text { angle }\left(^{\circ}\right)\end{array}$ & Depth $(\mathrm{m})$ & $\begin{array}{c}\text { Speed } \\
(\mathrm{m} / \mathrm{s})\end{array}$ & Location & Volume \\
\hline Case 1 & 40 & 0.74 & 0.3 & 1 & $1 \times 1.5 \times 0.2$ \\
Case 2 & 40 & 0.74 & 0.3 & 2 & $1 \times 1.5 \times 0.2$ \\
Case 3 & 40 & 0.74 & 0.3 & 3 & $1 \times 1.5 \times 0.2$ \\
Case 4 & 40 & 0.74 & 0.5 & 2 & $1 \times 1.5 \times 0.2$ \\
Case 5 & 40 & 0.74 & 0.7 & 2 & $1 \times 1.5 \times 0.2$ \\
Case 6 & 40 & 0.74 & 0.3 & 2 & $1 \times 0.5 \times 0.6$ \\
\hline
\end{tabular}

penetration into the water body, creates a large air cavity on the back of the slide.

Figure 7 shows that before the landslide body enters the water, the water level of each monitoring point in the river channel is zero, which was in a static state. The landslide body slides along the trough section and acts on the water body, causing fluctuations in water particles. Water particles were implicated on each other, causing water-level changes at the monitoring point. Changes in water-level values of the initial surge indicate that the initial wave of the rock landslide is random, and its shape is asymmetrical. The

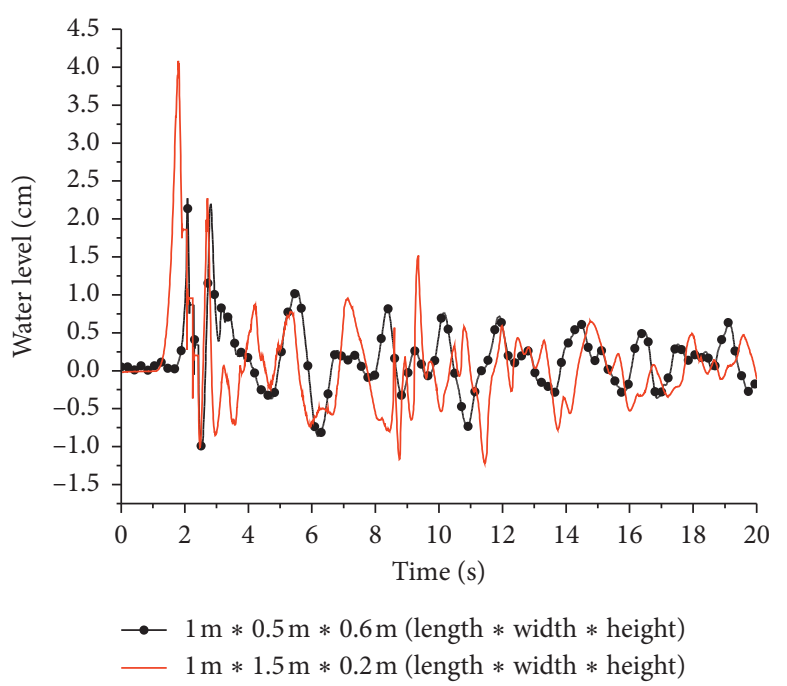

Figure 7: First landslide-generated wave height at different widthto-thickness ratios.

initial height under working case 2 was twice that of the initial height under working case 1 . Case 1 produced the peak value earlier than the working case 2 . The maximum wave crest amplitude was $4.082 \mathrm{~cm}$, and the maximum wave trough was $1.212 \mathrm{~cm}$. According to the scale ratio conversion, the actual wave crest height of the landslide-generated wave was $2.86 \mathrm{~m}$ and the actual wave trough height was $0.85 \mathrm{~m}$. Furthermore, working conditions 1 and 2 were affected by river topography, propagation distance, and river channel bending shape after maximum peak and trough occurrence. The monitoring point's wave energy and waterlevel value gradually decreased. The landslide body with the same landslide volume and different aspect ratios produced different characteristics of the landslide-generated wave. A larger width-to-thickness ratio resulted in a higher first wave of the landslide-generated wave, a larger wave energy, and a bigger impact on the hydraulic structure. Increase in the time and attenuation of the wave led to a gradual decrease in the landslide-generated wave's asymmetry, and the water surface became calm.

\section{Impact of Landslide and Surge on the Motion Characteristics of a Sailing Ship}

Ship stability prediction during the early stages of design was very important from the perspective of a vessel's safety. Of the six ship motions, the roll motion is a critical factor in ship capsizing. This section focuses on the roll motion characteristics of a ship in various cases.

5.1. Interaction between the Ship and Landslide-Generated Wave. Landslide-generated waves were classified into weakly nonlinear oscillatory and nonlinear transition. These classifications were based on the landslide Froude number and thickness at impact. It was found that nonlinear oscillation appeared at the Froude number $=1.6$ and nonlinear transition appeared at the Froude number $=2.9$. In this paper, we studied the interaction between the ship and 
landslide-induced wave. The main stages are shown in Figure 8.

The whole process can be subdivided into three main stages: (a) The formation of a landslide-generated wave: all the landslide bodies submerge in the model test, which reflects real-world situations. (b) The propagation of the landslide-generated wave: the crater collapses outward, resulting in the secondary wave. (c) Interaction between the ship and landslide-generated wave: a relative motion between a ship and fluid is a common occurrence.

\subsection{Effect of Ship's Roll Performance at Different Locations.}

This section mainly studies the effect of ship's roll performance on monitoring point 1 , monitoring point 2 , and monitoring point 3 in the region of landslide-generated wave, making the comparative analysis of ship's roll and roll angular velocity at different locations.

Roll motion is a major response of a ship in waves, which can be determined by analyzing various kinds of moments acting on the ship: virtual and actual mass moments of inertia, the roll damping moment, the restoring moment, wave excitation, and other moments caused by other modes of ship motion.

In this study, the ship sailed straight along the scheduled route at $0.3 \mathrm{~m} / \mathrm{s}$. The three tests followed the landslide at No. 1, No. 2, and No. 3 positions of focusing on the ship's roll. The landslide volume was $1 \mathrm{~m} \times 1.5 \mathrm{~m} \times 0.2 \mathrm{~m}$. Our focus was to study the variation law in the ship's roll angle and roll angular velocity.

According to the model test, the model ship in a landslide-generated wave moved with forward speed. As shown in Figure 9, in the three test condition locations, the ship's roll motion amplitude variation was within a reasonable range. The ship passed position No. 1, and the landslide body entered the water and exchanged energy with the water body. The ship's navigation direction was opposite to the wave propagation direction, and the landslide body entered the water. After $7 \mathrm{~s}$, the landslide-generated wave propagated to the navigation position and interacted with the ship, causing a large roll motion with $5.4^{\circ}$ maximum amplitude. The ship passed through position No. 3, and the landslide occurred. The ship's sailing direction was similar to the wave's propagation direction, i.e., in a state of landslide spur chasing the sailing ship. After the landslide body interacted with the water body for $10 \mathrm{~s}$, the landslide-generated wave propagated to the ship's navigation position, interacted with it, and acted on its tail, causing a smaller roll motion amplitude. The ship passed through position No. 2, which is close to the landslide point. After a landslide occurred for $3 \mathrm{~s}$, the ship's roll motion amplitude changed significantly. After passing through position No. 1, No. 2, and No. 3, the ship encountered a landslide-generated wave at different moments. The ship relies on its own restoring torque and slowly reaches equilibrium.

Figure 10 shows three cases of the physical test as the ship passes via position No. 1, No. 2, and No. 3. The amplitude of change in the ship's roll angular velocity at position No. 1 was the largest, followed by that of navigation position No. 2, whereas navigation position No. 3 was the smallest. The maximum wave amplitude was $35.37 \mathrm{deg} / \mathrm{s}$ at position No. 1. The moment of the initial change in the roll angular velocity was the same as that for the initial change in the roll angle, which occurred at the moment of interaction between the landslide-generated wave and ship. When the ship is sailing, higher roll angle speed causes worse comfort and less stable loading cargo. From this Figure 10, it can be observed that the ship's roll motion was affected at lowfrequency wave excitation. When the ship is sailing, sudden landslides occur, and the position of the landslide site is critical to the ship's safety. When the landslide point is in front of the ship, the speed of the ship should be controlled to increase the distance between the ship and landslide point. When the landslide point is located in the opposite direction of the ship's navigation, it should increase the speed of the ship to subjoin the distance between the ship and landslide point. This reduces the landslide's impact and surge on the sailing ship, improves the ship's navigation safety, enhances passenger comfort, and stabilizes the loading cargo.

\subsection{Effect of Ship's Rolling Characteristics at Different Navi-} gation Speeds. A landslide occurred when the ship passed through landslide location No. 2. The landslide volume was $1 \mathrm{~m} \times 1.5 \mathrm{~m} \times 0.2 \mathrm{~m}$, and the ship sailed in a straight line at $0.3,0.5$, and $0.7 \mathrm{~m} / \mathrm{s}$, respectively, guided by the variation law of the ship's roll angle and roll angle speed.

As shown in Figure 11, ships passing position No. 2 at different speeds experienced the same volume of landslides, but their roll motion amplitudes were different, with the largest reaching $15^{\circ}$ at a speed of $0.3 \mathrm{~m} / \mathrm{s}$. The landslide body position under the three cases was similar to the ship's navigation position. It can be noted here that the slight increase of drag in the high-speed range was due to the nonlinear lifting effect. Owing to the ships' different sailing speeds, the landslide-generated wave and time of the ship's action were slightly different. The roll motion curves of the ship under the three working conditions first increased nonlinearly, and then the nonlinearity was reduced. This is related to the ship sailing at different forward speeds, generated travelling waves, and landslide-generated wave. As time proceeded, the ship gradually returned to the shortrange fluctuation state by relying on its own recovery torque. When the ship moved at $0.3 \mathrm{~m} / \mathrm{s}$, the roll amplitude was large, which is cause for concern.

The experimental data were combined with the ship's construction-optimizing keel size and increasing ship damping were considered in the landslide-generated wave region. Changing the external load's influence on the hull pressure distribution and water depth in the ballast tank prevented water movement from hitting the top of the antirolling tank when the ship's roll motion amplitude became larger, which also reduced the antishake effects of the system.

Figure 12 indicates that a ship passing track line position No. 2 at $0.3,0.5$, and $0.7 \mathrm{~m} / \mathrm{s}$ had different time-history curves of ship's roll angular velocity. The roll speed corresponding to the forward speed of $0.3 \mathrm{~m} / \mathrm{s}$ was most affected 


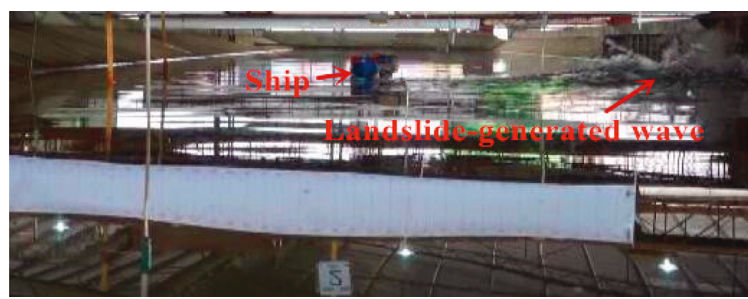

(a)

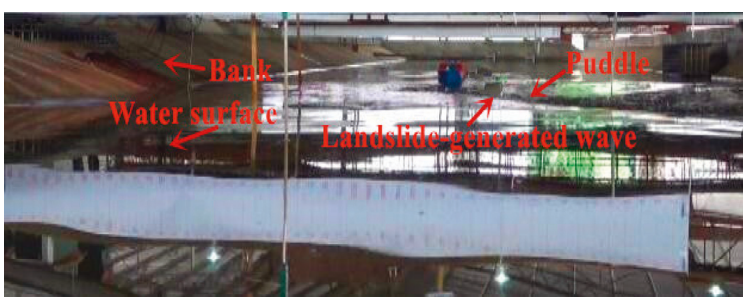

(b)

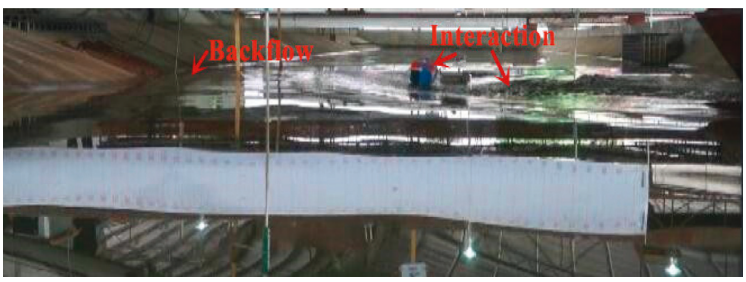

(c)

Figure 8: Main stages of interaction between a ship and a landslide-generated wave. (a) The formation of a landslide-generated wave; (b) the propagation of a landslide-generated wave; (c) the interaction between a ship and a landslide-generated wave.

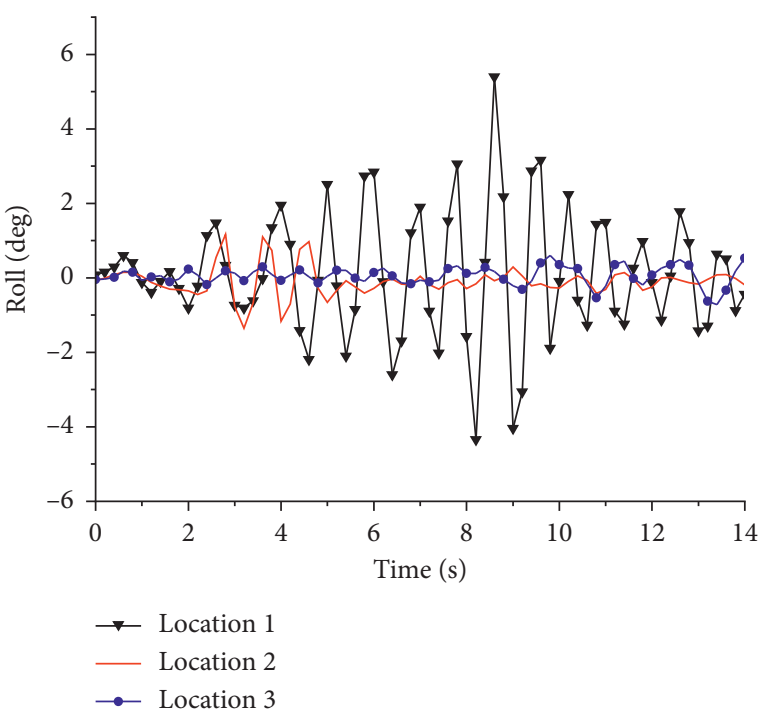

FIGURE 9: Ship's roll-time curve at different navigation positions.

by the landslide-generated wave. The maximum value reached $95^{\circ} / \mathrm{s}$. Concurrently, when the ship's sailing speed was slow, the impulse load of the landslide-generated wave acted on the hull, the roll angular velocity curve of the hull first changed, and the roll angular velocity curve of the ship began to change at $0.8 \mathrm{~s}$. Under the landslide's influence, the roll angle reached its maximum value in $3 \mathrm{~s}$, showing a very strong transient nature. Furthermore, the action process was accompanied by a high roll angle velocity, which adversely affected passenger comfort and the loaded cargo's stability.

5.4. Influence of the Rolling Characteristics of a Ship at Different Ratios. The landslide occurred when the ship passed through location No. 2. The landslide body dimensions were $1 \mathrm{~m} \times 1.5 \mathrm{~m} \times 0.2 \mathrm{~m}$ and $1 \mathrm{~m} \times 0.5 \mathrm{~m} \times 0.6 \mathrm{~m}$, and the ship

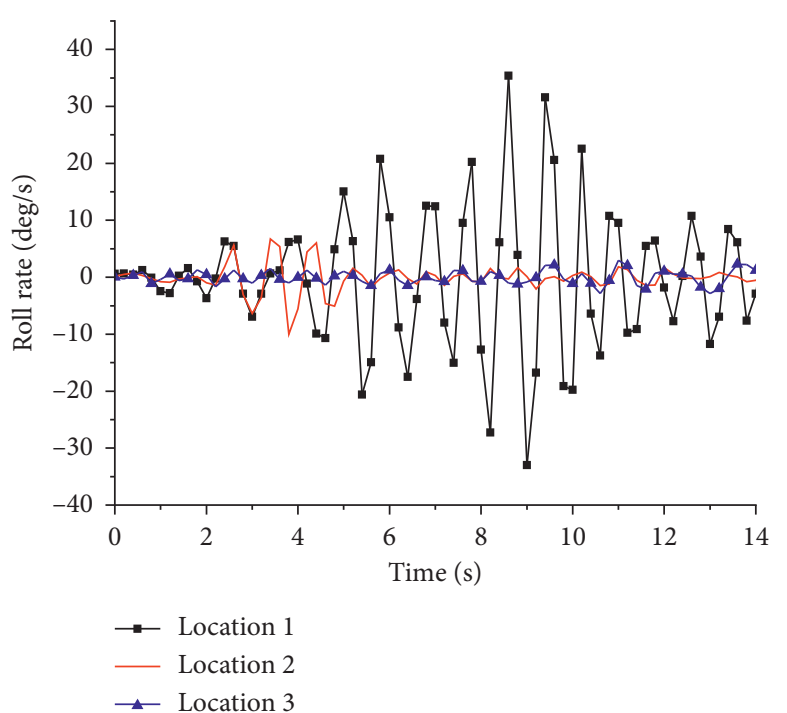

FIGURE 10: Time-history curve of the ship's roll angular velocity at different navigation positions.

sailed at a fixed speed of $0.3 \mathrm{~m} / \mathrm{s}$ in a straight line, with emphasis on the ship's roll angle and variation in its angular velocity.

Figure 13 demonstrates that when the landslide body entered the water at a high speed, it was accompanied by a high-pressure peak. However, when a landslide body with the same volume and different ratios entered the water, the impact load size was different. A large difference in roll was also observed. Wave height contributes significantly to roll movement; when the landslide-generated wave propagates in the channel, the roll motion is dramatically reduced. The width-thickness ratio under working condition 6 was small; hence, the ship's roll motion peak appeared earlier. The load between the landslide and water body was small, and the amplitude of the roll motion was small. The aspect ratio under working condition 3 was large, and the peak of the 


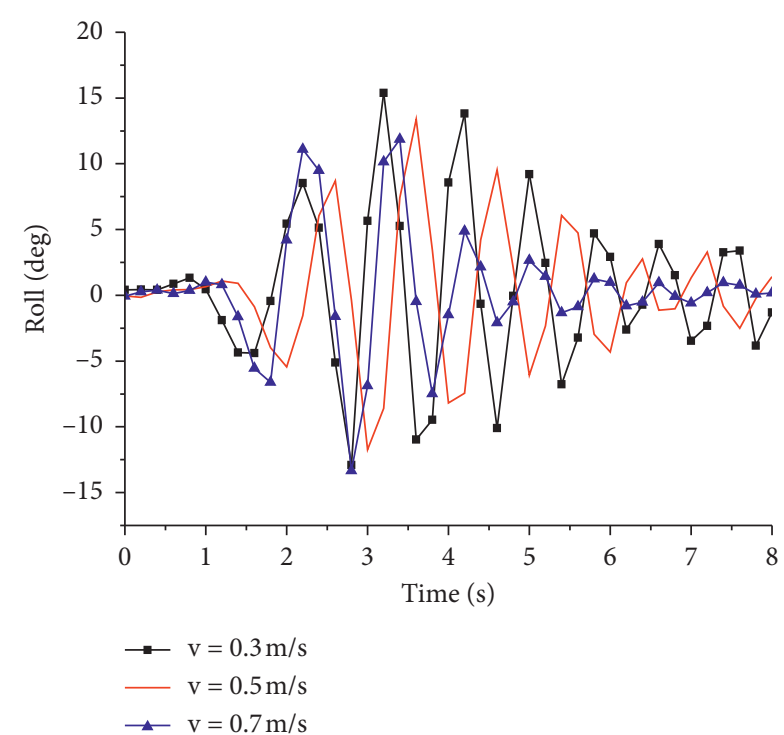

FIgURE 11: Ship's roll time-history curve for different speeds.

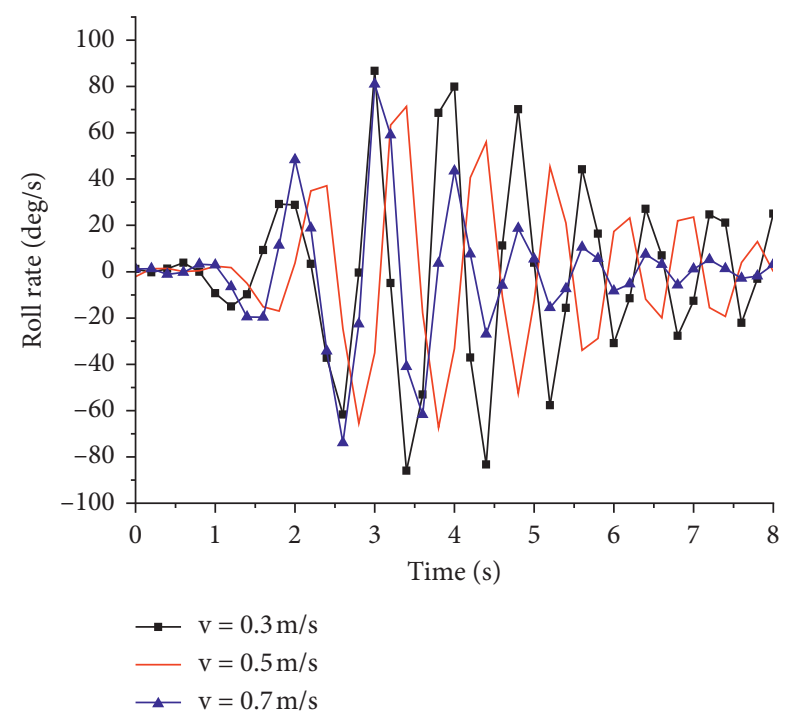

FIGURE 12: Ship's roll angular velocity time-history curve at different ship speeds.

ship's roll motion had a certain delay. Furthermore, the roll motion's amplitude was large, reaching $15^{\circ}$, which was close to the ultimate roll angle of the navigation in the reservoir area. A larger aspect ratio with the same landslide body amount has a larger impact on the ship's roll characteristics, leading to worse ship navigation safety. In actual disaster prevention projects, to reduce the effect of a landslidegenerated wave on the hydraulic structures, the width-tothickness ratio of the smaller rock mass is reduced and treated in stages to prevent large-scale mountain landslides.

Figure 14 shows that the fixed speed of the ship was $0.3 \mathrm{~m} / \mathrm{s}$ straight ahead, and landslides with different ratios occurred through landslide No. 2 . The landslide bodies with the same volume and different aspect ratios had different effects on the ship's roll angular velocity, and the asymmetry of the landslide-generated wave led to angular velocity

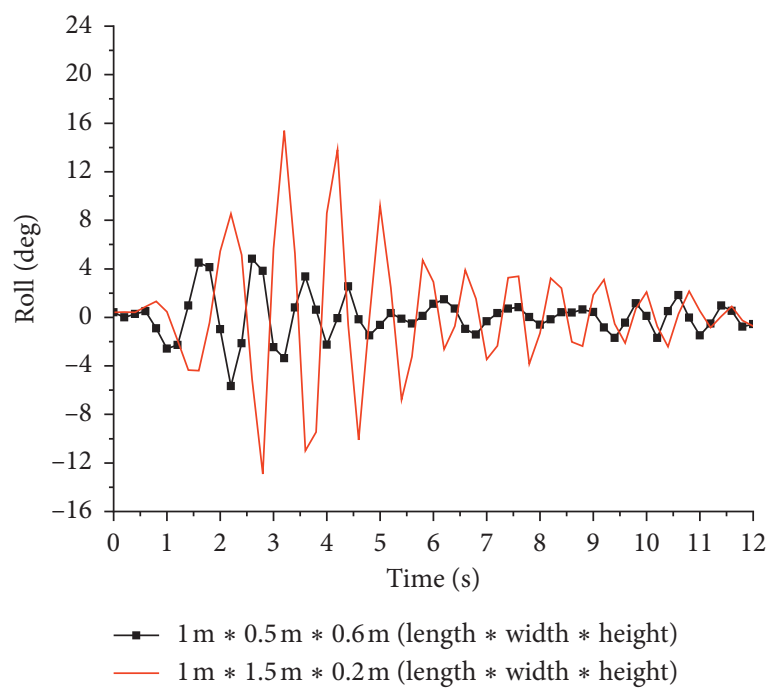

Figure 13: Roll time-history curve with different landslides.

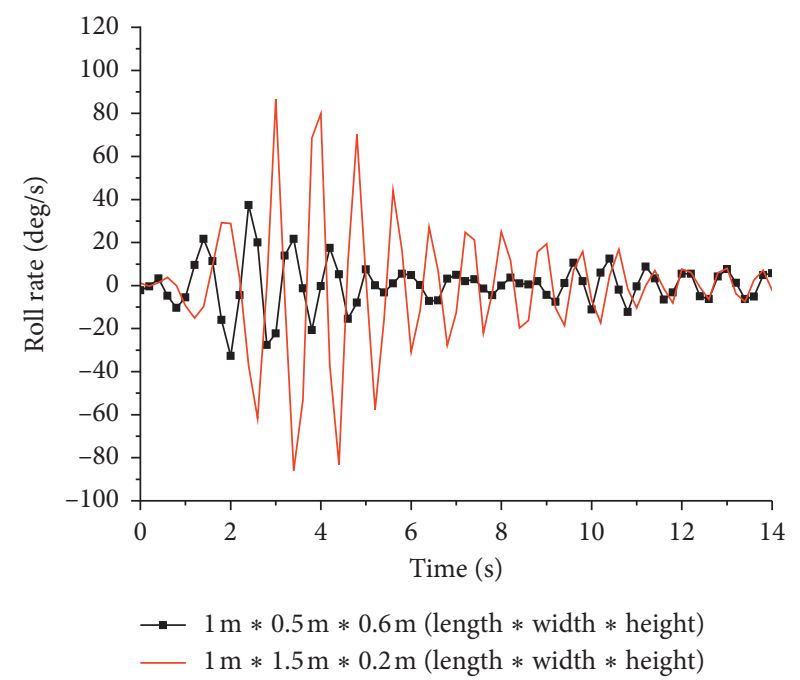

FIGURE 14: Ship's roll angular velocity time-history curve for different landslides.

asymmetry of the ship. The landslide body with a significant thickness had a major effect on the ship's roll angular velocity. The maximum value was $90^{\circ} \mathrm{s}$. From this Figure 14, the motions of both roll movement and roll angular velocity were in good agreement with the landslide-generated wave. A landslide body of relatively less thickness had little influence on the ship's roll angular velocity. Two types of landslide bodies enter the water to produce a landslidegenerated wave. The action process of the landslides is consistent with the ship. The roll angular velocity of the ship increases instantaneously in a short period. After some time, the landslide-generated wave energy is attenuated. The ship relies on its own restoring force to reduce the roll angle and roll angular speeds, allowing it to reach a relatively stable state. and Travelling States. When the ship is stationary or sailing 
at $0.6 \mathrm{~m} / \mathrm{s}$ through the waters of a landslide section, landslides occur (Figure 15). These landslides present adverse effects on stationary and sailing ships. Landslide impacts on ships sailing at $0.6 \mathrm{~m} / \mathrm{s}$ are divided into two stages: The first stage occurs within 1-5 s. When the landslide body enters the water, the impact generates a landslide wave and the liquid splashes significantly, accompanied by the waves on the deck. As the ship has been sailing straight, the landslidegenerated wave acts on the middle and rear parts of the ship. Thus, a large amplitude of swaying motion is easily produced, and the motion amplitude change rate is steep. The second stage occurs at $11-18 \mathrm{~s}$, caused by the landslidegenerated wave. The direction is transmitted, finally reaching the end of the river, thereby impacting the bank slope, forming reflection, reflow, and superimposing the impact of the synthetic wave on the sailing ship. The first stage's maximum roll motion amplitude was $10^{\circ}$. The maximum roll motion of the second-stage ship was $9^{\circ}$. When the ship encounters a landslide during the actual navigation process, it should focus on controlling the navigation speed and water field instability to prevent the landslide-generated wave from causing a "secondary damage" to the ship. The ship is stationary in the waters of the landslide section, and the landslide body generates a landslide-generated wave after entering the water. The ship's roll motion amplitude appeared at 1-14s, showing a single peak state, with the landslide's wave energy gradually decreasing along the landslide. The ship relies on its own recovery torque and recovery damping. The amplitude of the roll motion gradually decreased, and eventually stabilized. The ship was stationary in the sluice waters. It is necessary to focus on the landslide starting moment and prevent the landslide. The impact of the first wave on the ship, reasonable and effective disaster prevention, and mitigation procedures should be considered.

\section{Discussion and Conclusions}

In this paper, we discussed the design of a landslide surge model in rivers based on a physical test model. We mainly focused on the influence of the pulse surge generated by landslides, having the same volume but different aspect ratios, on a ship's rolling characteristics. We further studied the effects of the same landslide on the ship's rolling characteristics at different cruising speeds. The rolling characteristics of the landslide-generated wave were examined before the ship reached different positions. The main conclusions are as follows:

(1) After the diffraction and superimposition of the reflected waves, a large wave momentum implies a greater influence on the hydraulic structure. For the same $0.6 \mathrm{~m}^{3}$ volume of landslide bodies, a larger width-to-thickness ratio implies a greater height of the first landslide wave, the width-to-thickness ratio is $1: 9$; the maximum value ratio is about $1: 2$, and maximum value is $2.86 \mathrm{~m}$.

(2) When the ship sails and sudden landslides occur, the position of the landslide site is critical to the ship's safety. When ship's navigation direction was

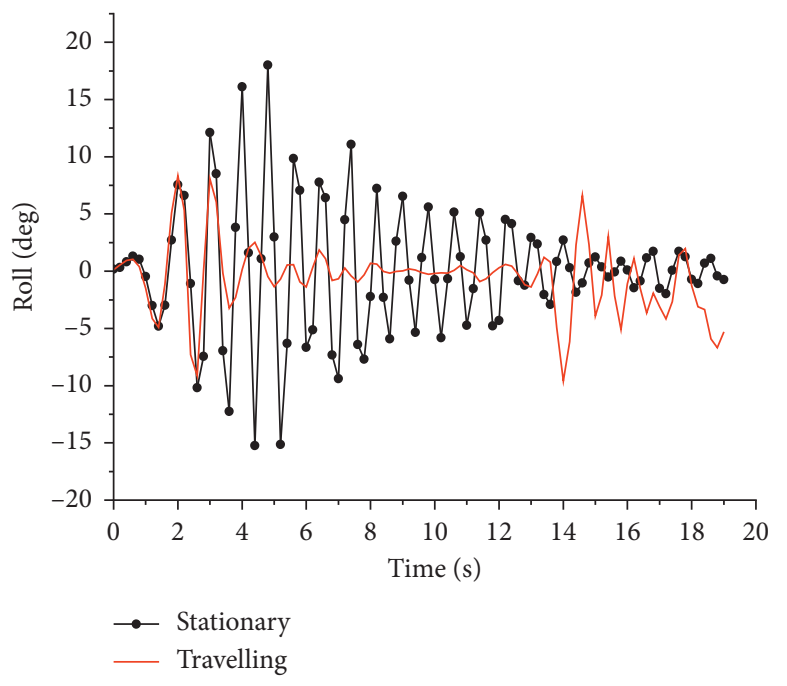

FIgURE 15: Ship's roll time-history curve.

opposite to the wave propagation direction, the frequency of ship motion is more violent, the maximum value is $5.4 \mathrm{deg}$, and the maximum roll angular velocity is $35.37 \mathrm{deg} / \mathrm{s}$.

(3) During a voyage, a ship suddenly encounters a landslide-generated wave. The impulse surge generated by the same volume of landslides has different effects on the ships at different voyage speeds. The maximum roll angle and roll angular velocity are $15.39 \mathrm{deg}$ and $86.72 \mathrm{deg} / \mathrm{s}$, respectively, at a speed of $0.3 \mathrm{~m} / \mathrm{s}$. In order to increase passenger comfort and cargo-loading safety, the sailors should take the initiative to reduce the ship's speed by reducing the acceleration itself.

(4) The roll motion characteristic curve of stationary and travelling ships is totally different. A travelling ship generates waves, which lead to other overlapping complicated waves; thus, the period of wave and roll motion appears twice. The first roll motion curve of travelling ships has two large crests: the first peak value is $8.34 \mathrm{deg}$ and the second peak value is $6.62 \mathrm{deg}$; both are in the reasonable portion. While the other has one large crest, the maximum value is $18.02 \mathrm{deg}$.

\section{Data Availability}

The data in figures and tables used to support the findings of this study are included herein.

\section{Conflicts of Interest}

The authors declare that they have no conflicts of interest.

\section{Acknowledgments}

This study was financially supported by the National Natural Science Foundation (51479015) and the Social Science and Technology Innovation Program for People's Livelihood 
in Chongqing (cstc2018jscx-msybx0233, cstc2017shmszdyfX0026, cstc2018jszx-cyzdX0019, cstc2018jszxzdyfxmX0013, and cstc2017jcyjBX0070).

\section{References}

[1] H. M. Fritz, W. H. Hager, and H.-E. Minor, "Landslide generated impulse waves," Experiments in Fluids, vol. 35, no. 6, pp. 505-519, 2003.

[2] B. Ataie-Ashtiani and A. Nik-Khah, "Impulsive waves caused by subaerial landslides," Environmental Fluid Mechanics, vol. 8, no. 3, pp. 263-280, 2008.

[3] S. Yavari-Ramshe and B. Ataie-Ashtiani, "A rigorous finite volume model to simulate subaerial and submarine landslidegenerated waves," Landslides, vol. 14, no. 1, pp. 203-221, 2017.

[4] H. M. Fritz, W. H. Hager, and H.-E. Minor, "Landslide generated impulse waves. 2. Hydrodynamic impact craters," Experiments in Fluids, vol. 35, no. 6, pp. 520-532, 2003.

[5] F. Evers, Spatial Propagation of Landslide Generated Impulse Waves, Ph.D. thesis, ETH Zurich, Zurich Switzerland, 2017.

[6] V. Heller, W. H. Hager, and H.-E. Minor, "Scale effects in subaerial landslide generated impulse waves," Experiments in Fluids, vol. 44, no. 5, pp. 691-703, 2008.

[7] E. Noda, "Water waves generated by landslide," J. Water Port. Coast Ocean Div. Am. Soc. Civ. Eng., vol. 96, pp. 835-855, 1970.

[8] J. Kamphuis, "Impulse waves generated by landslides," in Proceedings of the 12th Coastal Engineering Conference, pp. 575-588, Washington, DC, USA, 1970.

[9] D. Muller, "Impulse waves generated by an artificially induced rockfall in a Swiss lake," in Proceedings of the 25th IAHR Congress, vol. 4, pp. 209-216, Tokyo, Japan, August-September 1993.

[10] K. Yin, "Physical model experiments of landslide-induced surge in three Gorges reservoir," Earth Science, vol. 37, pp. 1067-1074, 2012.

[11] M. Risio and P. Sammarco, "Analytical modeling of landslidegenerated impulse waves," Journal of Waterway, Port, Coastal, and Ocean Engineering, vol. 134, no. 1, pp. 53-60, 2008.

[12] C. F. Waythomas and P. Watts, "Numerical simulation of tsunami generation by underwater landslides," Journal of Waterway, Port, Coastal, and Ocean Engineering, vol. 124, pp. 127-137, 1998.

[13] S. M. Abadie, J. C. Harris, S. T. Grilli, and R. Fabre, "Numerical modeling of tsunami waves generated by the flank collapse of the Cumbre Vieja Volcano (La Palma, Canary Islands): tsunami source and near field effects," Journal of Geophysical Research: Oceans, vol. 117, no. 5, 2012.

[14] V. Heller, W. H. Hager, and H. Minor, Landslide Generated Impulse Waves in Reservoirs-Basics and Computation, Versuchsanstalt fur Wasserbau, Zurich, Switzerland, 2009.

[15] H. Tan, G. Ruffini, V. Heller, and S. Chen, "A numerical landslide-tsunami hazard assessment technique applied on hypothetical scenarios at Es Vedrà, offshore Ibiza," Journal of Marine Science and Engineering, vol. 6, no. 4, pp. 1-22, 2018.

[16] G. Ma, F. Shi, and J. T. Kirby, "Shock-capturing non-hydrostatic model for fully dispersive surface wave processes," Ocean Model, vol. 43, pp. 22-35, 2013.

[17] V. Heller and W. H. Hager, "Wave types of landslide generated impulse waves," Ocean Engineering, vol. 38, no. 4, pp. 630-640, 2011.

[18] V. Heller and J. Spinneken, "Improved landslide-tsunami prediction: effects of block model parameters and slide model," Journal of Geophysical Research: Oceans, vol. 118, no. 3, pp. 1489-1507, 2013.

[19] V. Heller and J. Spinneken, "On the effect of the water body geometry on landslide-tsunamis: physical insight from laboratory tests and 2D to 3D wave parameter transformation," Coastal Engineering, vol. 104, pp. 113-134, 2015.

[20] V. Heller, M. Bruggemann, J. Spinneken, and B. D. Rogers, "Composite modelling of subaerial landslide-tsunamis in different water body geometries and novel insight into slide and wave kinematics," Coastal Engineering, vol. 109, pp. 20-41, 2016.

[21] L. Nie, Z. Gao, G. Zhu, and Z. Pan, "Study on dynamic responses of duct-water coupled components for aqueduct with seismic isulation," Journal of Hydroelectric Engineering, vol. 30, no. 6, pp. 62-66, 2011.

[22] J. L. Cercos-Pita, G. Bulian, L. Pérez-Rojas, and A. Francescutto, "Coupled simulation of nonlinear ship motions and a free surface tank," Ocean Engineering, vol. 120, pp. 281-288, 2016.

[23] K. J. Spyrou and I. G. Tigkas, "Nonlinear surge dynamics of a ship in astern seas: "continuation analysis" of periodic states with hydrodynamic memory," Journal of Ship Research, vol. 55, pp. 19-28, 2011.

[24] G. C. Soares and N. Fonseca, "Abnormal wave-induced load effects in ship structures," Journal of Ship Research, vol. 52, pp. 30-44, 2008.

[25] Y. Kim, B. W. Nam, D. W. Kim, and Y. S. Kim, "Study on coupling effects of ship motion and sloshing," Ocean Engineering, vol. 34, no. 16, pp. 2176-2187, 2007.

[26] O. Faltinsen and R. Zhao, "Numerical predictions of ship motions at high forward speed," Philosophical Transactions of the Royal Society of London. Series A: Physical and Engineering Sciences, vol. 334, pp. 241-252, 1991.

[27] S. K. Das and S. N. Das, "Note on sway, roll and yaw motions of a ship with forward speed: analytical study," Acta Mechanica, vol. 186, no. 1-4, pp. 221-227, 2006.

[28] S. K. Das and S. N. Das, "Modelling and analysis of coupled nonlinear oscillations of a floating body in two degrees of freedom," Acta Mechanica, vol. 181, no. 1-2, pp. 31-42, 2006.

[29] M. Soylemez, "Motion response simulation of a twin-hulled semisubmersible," Ocean Engineering, vol. 25, pp. 359-383, 1998.

[30] K. Mctaggart, "Lateral ship motions and sea loads in waves including appendage and viscous forces," International Shipbuilding Progress, vol. 47, pp. 141-160, 2000.

[31] H. Hatecke, "The impulse response fitting and ship motions," Ship Technology Research, vol. 62, no. 2, pp. 97-106, 2015.

[32] S. Murashige and K. Aihara, "Experimental study on chaotic motion of a flooded ship in waves," Proceedings of the Royal Society of London. Series A: Mathematical, Physical and Engineering Sciences, vol. 454, no. 1978, pp. 2537-2553, 1998.

[33] R. Pethiyagoda, T. J. Moroney, G. J. Macfarlane, J. R. Binns, and S. W. McCue, "Time-frequency analysis of ship wave patterns in shallow water: modelling and experiments," Ocean Engineering, vol. 158, pp. 123-131, 2018.

[34] S. Sigmund and O. el Moctar, "Numerical and experimental investigation of added resistance of different ship types in short and long waves," Ocean Engineering, vol. 147, pp. 51-67, 2018.

[35] N. Fonseca and C. Guedes Soares, "Comparison of numerical and experimental results of nonlinear wave-induced vertical ship motions and loads," Journal of Marine Science and Technology, vol. 6, no. 4, pp. 193-204, 2002.

[36] P. Heinrich, "Nonlinear water waves generated by submarine and aerial landslides," Journal of Waterway, Port, Coastal, and Ocean Engineering, vol. 118, pp. 223-238, 1992. 


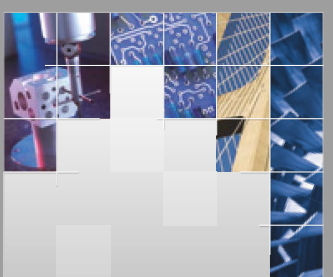

\section{Enfincering}
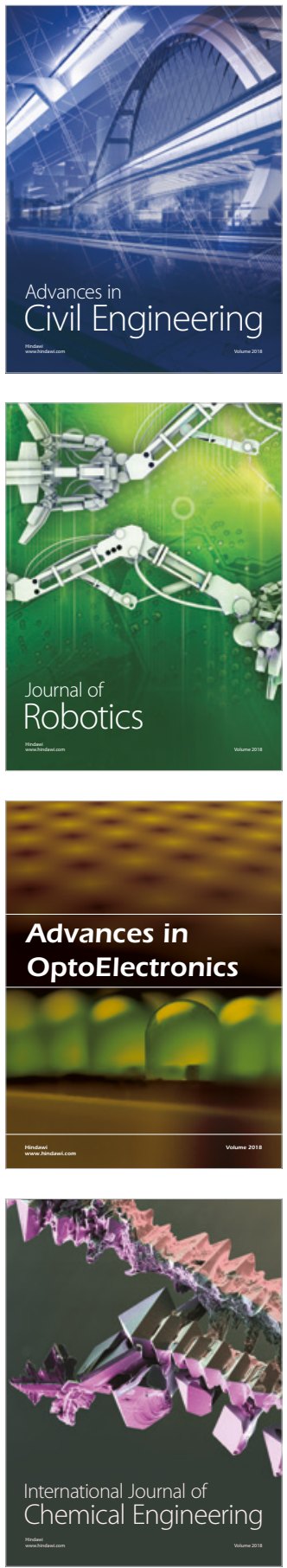

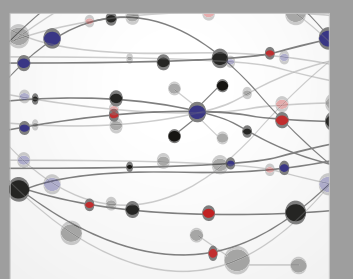

\section{Rotating \\ Machinery}

The Scientific World Journal

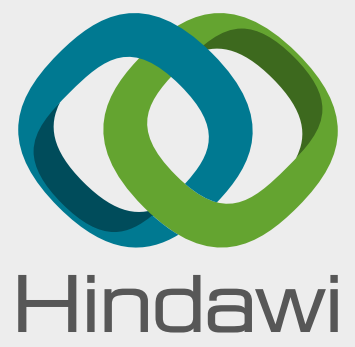

Submit your manuscripts at

www.hindawi.com
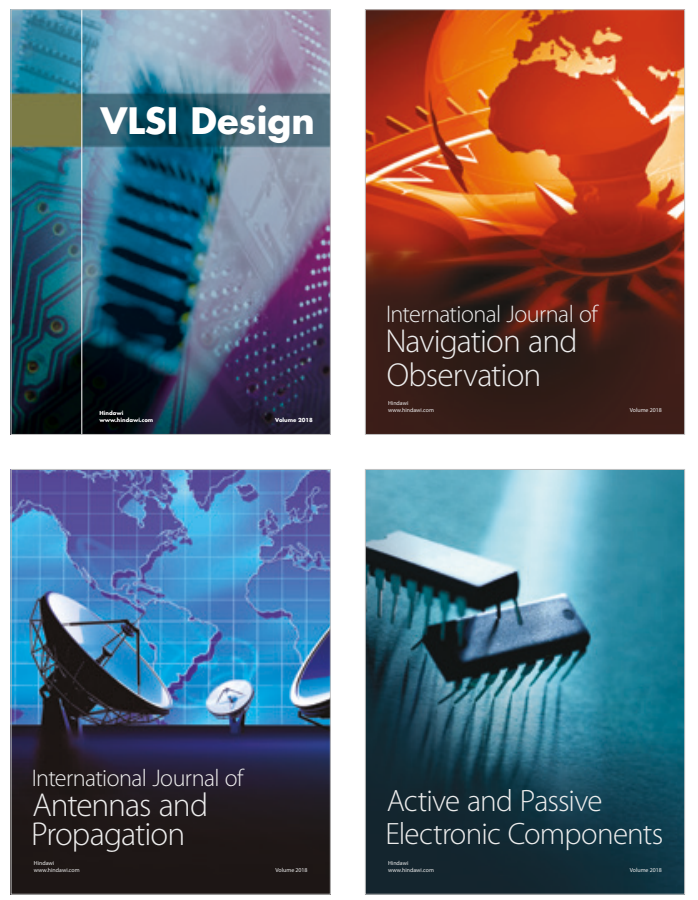
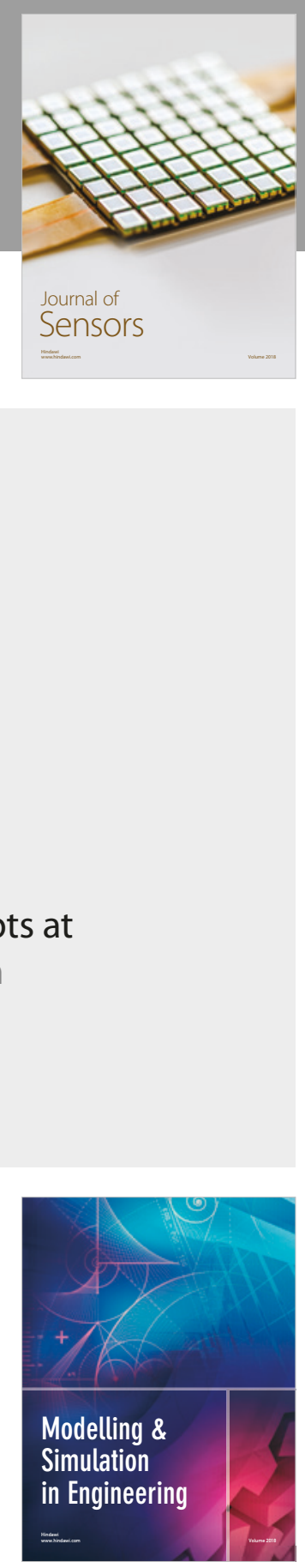

\section{Advances \\ Multimedia}
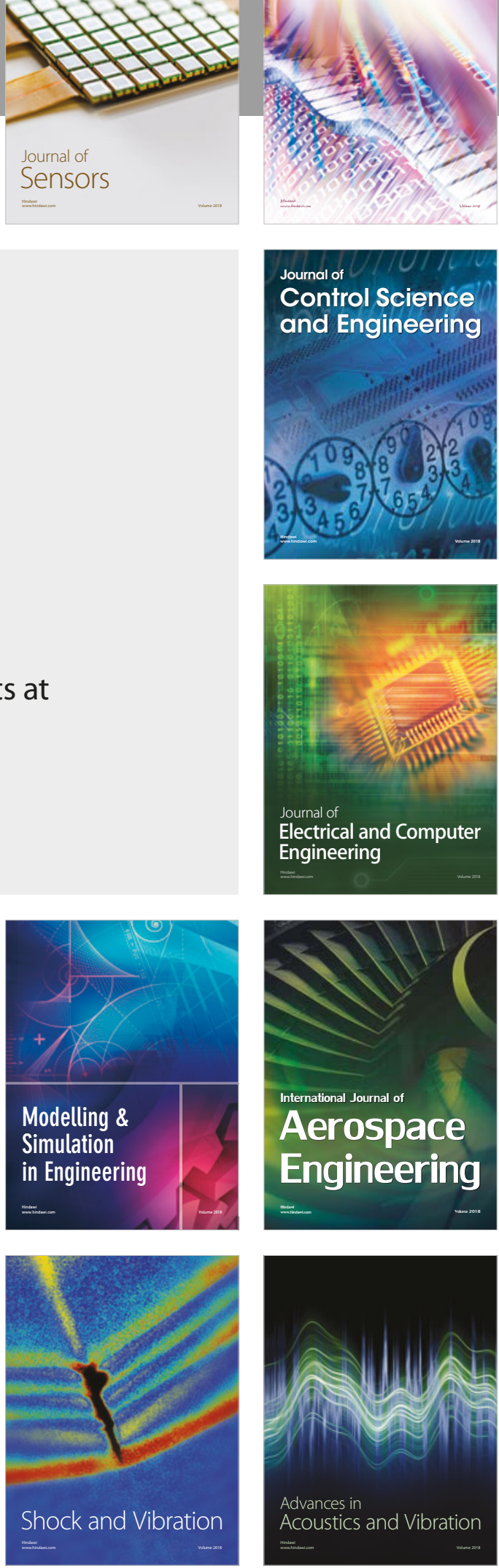